PEDAGOGISK FORSKNING I SVERIGE Vol. 26 No. 2-3 (2021) ISSN 1401-6788

\title{
NOTAT
}

\section{Kollegial bedömning vid rekrytering av universitetslärare ${ }^{1}$}

\author{
Eva Forsberg \\ Uppsala universitet \\ Sara Levander \\ Högskolan i Gävle
}

Samhällsutvecklingen och förändringar av den högre utbildningens ledning och organisation har haft en avgörande betydelse för formeringen av den akademiska professionen och dess autonomi (Whitley, 2011). Omvänt är akademins framtid och dess bidrag till det omgivande samhället i hög grad beroende av vilka som rekryteras som lärare, forskare och doktorander (Teichler \& Cummings, 2015). Rekrytering och befordran påverkar inte bara vilken forskning och vilka utbildningar som prioriteras och hur lärosäten och discipliner kan utvecklas, utan också enskilda akademikers karriärvägar. Ytterst handlar det om vilken kunskap som produceras och reproduceras och görs tillgänglig för samhället (Musselin, 2010).

Den akademiska professionen är lärosätenas centrala kapital (Bourdieu, 1996) och den kollegiala bedömningen utgör fundamentet i rekryteringen av universitetsläraren (Langfeldt \& Kyvik, 2011). I vetenskapssamfundet går kollegial bedömning under beteckningen 'peer review' eller 'scholarly refereeing'. Historiska analyser länkar den till distribueringen av auktoritet och förhandlingar om vetenskapens status (Czisar, 2016). Omväxlande omtalas 'peer review' som 'the linchpin of science' (Ziman, 1968), som en hörnsten i det akademiska karriärsystemet och granskarna (peers) som grindvakter (gatekeepers) av vetenskaplig kvalitet och kommunikation (Merton, 1968). 
Peer review betraktas också som en väsentlig del av kollegialiteten och meritokratin (Cole \& Cole, 1973) och idag som något som genomsyrar varje hörn av akademin (Tennant \& Ross-Hellauer, 2020).

Dess användning inom akademin har ökat i antal och den har också spritts till nya områden. Vid anställning av både lektorer och professorer så har över lång tid sakkunnigförfarande haft en avgörande betydelse för prioritering och selektion mellan sökande. Formerna för kollegial bedömning och redskapen som brukas samt processerna de ingår i varierar över tid och rum och i skilda akademiska kontexter.

Mot denna bakgrund är det föga förvånande att kollegial bedömning under de senaste åren blivit ett objekt av stort intresse för professionella och ledningar (Oancea, 2019). Det gäller också forskningen om kollegial bedömning, även om det alltjämt är ett understuderat fenomen, särskilt vid rekrytering och befordran (Sabaj Meruane et al., 2016). Därför är det extra angeläget att vi som praktiker uppmärksammar och reflekterar över dessa processer och som forskare undersöker och analyserar den kollegiala bedömningen liksom dess villkor, förändringar och konsekvenser.

Kollegial bedömning omfattar utvärderingspraktiker av skilda slag, men vi avgränsar oss här till kollegial bedömning vid rekryteringen av lektorer och professorer, med Sverige som exempel. Inledningsvis fokuserar vi rekrytering inom akademin som processer som utmärks av såväl stabilitet som förändring. Därnäst illustrerar vi hur processen kan se ut och den kollegiala bedömningens position och roll i processen. På det följer ett avsnitt där vi riktar intresset mot grindvaktens kvalifikationer och uppgifter. Avslutningsvis redogör vi kortfattat för forskningsläget samtidigt som vi riktar blicken mot framtiden.

\section{FORMERINGEN AV DEN AKADEMISKA PROFESSIONEN: MELLAN STABILITET OCH FÖRÄNDRING}

Den akademiska professionen är av tradition inbäddad i det internationella vetenskapssamfundet och dess disciplinära fält med skilda epistemiska kulturer, associationer, nätverk, konferenser och vetenskapliga tidskrifter och till dessa knutna kollegiala bedömningar (Merton, 1968; Becher, 1989). Professionen har också sin förankring $\mathrm{i}$ de nationella systemen för högre utbildning och dess olika typer av institutioner för utbildning och/eller forskning. Att universitet och discipliner utmärks av stabilitet som när de förändras endast gör det i små steg är inte okänt (Clark, 1989). De senaste 40 åren har emellertid omfattande förändringar genomförts av styrningen av högre utbildning med exogena styrningsmekanismer och institutionalisering av system för kvalitetssäkring som följd. Denna utveckling är integrerad och relaterad till processer som massifiering, marknadisering, managerialism och 
digitalisering (Whitley, 2011). Det innebär att förskjutningar och omförhandlingar har skett mellan stat, marknad och akademi i ansvaret för den högre utbildningen (Musselin, 2010).

Genom nationers och lärosätens medverkan i olika internationella sammanhang har den akademiska professionen även knutits allt starkare till globaliseringen av den högre utbildningen. Denna rörelse omfattar bland annat utformande av gemensam policy, struktur, konferenser, program, projekt och priser som till exempel Bolognaprocessen, Charter \& Code for researchers, ESG - Standards and guidelines for quality assurance in the European Higher Education Area. Komparativa studier av högre utbildning i olika länder visar att den akademiska professionen formas i ett spänningsfält mellan stabilitet och förändring (Teichler \& Höhle, 2013). Världen över kan konvergens och en tilltagande standardisering iakttas samtidigt som avgörande skillnader kvarstår eller återuppstår på nationell, institutionell och disciplinär nivå (Teichler \& Cummings, 2015).

I Sverige kan vi iaktta den internationella samordningen $i$ form av anslutningen till överenskommelser och inriktningar av ovan nämnt slag. Samtidigt finns också en kvarvarande stark nationell reglering genom högskolelag, högskoleförordning och former för finansiering. Till detta kommer genom autonomireformen 2011 en ökad institutionell variation med växande utrymme för ledningar och möjlighet för lärosäten utforma anställnings- och arbetsordningar samt karriärvägar för lärare och forskare som skiljer sig åt (Forsberg et al., u.u.). Till detta kan fogas disciplinberoende skillnader vid kollegial bedömning i rekrytering (Levander, 2017), även vid införandet av nya redskap i granskningen såsom bibliometri et cetera (Hammarfelt \& Rushforth, 2017).

\section{REKRYTERINGSPROCESSEN - FRÅN FÖRHANDLING TILL BESLUT}

Akademin rymmer många olika typer av läraranställningar och sammanhangen för dessa skiljer sig åt. Det handlar om såväl rekryteringens inriktning (forskning, utbildning) och rang (adjunkt, lektor, professor) som skilda epistemiska kulturer och traditioner. Nedanstående exempel på rekryteringsprocessen i ett antal steg utgör dock en schematisk illustration av hur det kan se ut vid många universitet. Formellt sett startar processen med ett beslut om rekrytering (1). Ofta är dessa beslut inbäddade i ställningstaganden utifrån lärosätets akademiska profil och lokala behov, och har föregåtts av överväganden och förhandlingar på fakultets- och/eller institutionsnivå. Här ingår också förankring och utarbetande av anställningsprofil. När beslut om rekrytering är fattat utlyses anställningen (2). Utlysningarna är särskilt intressanta eftersom de aktualiserar frågor om inriktningar och bredd samt allmänna kriterier och deras specifika viktning i aktuell utlysning. När sökande skickat in sina ansökningshandlingar (3), är nästa steg i processen val av 
sakkunniga (4). Detta görs i normalfallet av lärarförslagsnämnd eller motsvarande. Vanligtvis väljs två externa sakkunniga ut för att bedöma de sökandes vetenskapliga och pedagogiska skicklighet, samt övriga meriter som till exempel lednings- eller administrativ skicklighet. Urval av sakkunniga innebär även preciseringar av uppdrag och kommunikation kring vägledningar och kriterier, och sakkunnigutlătandets utformning och resultat. Det sistnämnda handlar om huruvida sakkunniga enbart ska urskilja en tätgrupp, eller även göra en slutlig rangordning av de mest meriterade i sökfältet. Sakkunnigas utlătanden (5) bildar sedan tillsammans med de sökandes ansökningshandlingar, intervjuer med sökanden och eventuella provföreläsningar grunden för lärarförslagsnämndens överläggningar (6) och förslag till beslut (7). Det slutliga beslutet (8) tas av prefekt eller rektor beroende på vilket typ av anställning det är frågan om. Hit hör också avslutande förhandlingar avseende lön och resurstilldelning. I förekommande fall överklagas det slutliga beslutet av någon eller några sökanden (9). Hela processen illustreras i figur 1 .

Figur 1. Process vid rekrytering av universitetslärare

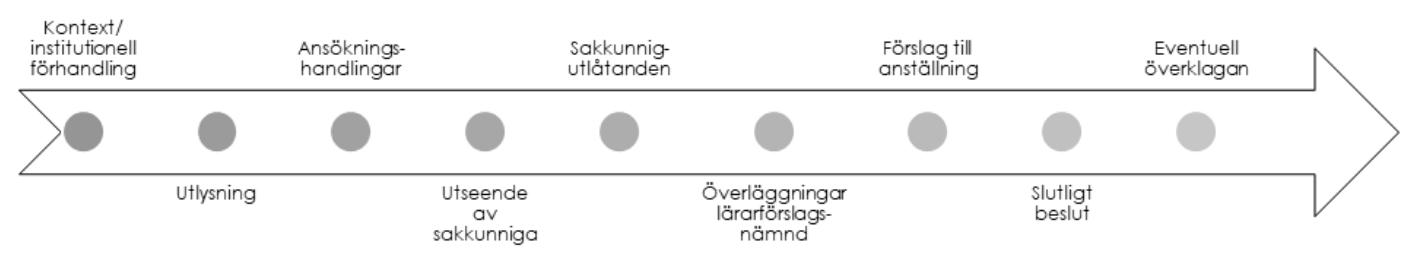

Som framgår ovan och av figuren rymmer rekryteringsprocessen som den kollegiala bedömningen ingår i förankringar, förhandlingar och beslut som i sin tur är inramade av regleringar, vägledningar och dokument av många olika slag. Det är en i hög grad maktbemängd process som sakkunniginstitutionen är inbäddad i.

\section{SAKKUNNIGINSTITUTIONEN - EN LEGITIMERING AV VÄRDE OCH FÖRTJÄNSTER}

I Sverige har rekrytering av universitetslärare under lång tid varit en angelägen fråga för policy och praktik. Med etableringen av sakkunniginstitutionen i slutet av 1800-talet sattes kollegial bedömning i förgrunden och genom offentlighetsprincipen och strävan efter opartiskhet framhölls en förväntan på dokumentation, öppenhet och likabehandling på meritokratiska grunder. 
Kollegial bedömning är en social utvärderingsprocess där värde, förtjänster och betydelser produceras, sprids och bedöms (Scriven, 2003). Ytterst är bedömningen en legitimering och institutionalisering av akademiska produkter och deras producenter (Lamont, 2009). Gemensamt för den kollegiala bedömningen är sökandes inskickade underlag och lärosätens kriterier som grund för bedömningar. Rekryteringsprocesser utmärks av en hög grad av osäkerhet. Att urskilja och fastställa kvalitet är svårt och följaktligen också att jämföra och rangordna sökande. I dessa processer av selektion och legitimering är frågor som refererar till kriterier, standards, bedömning och rangordning signifikanta. Attribut som ofta förs fram som tecken på forskning av god kvalitet är originalitet, tillförlitlighet och värde eller användbarhet (Langfeldt et al., 2020). Men att identifiera kvalitet och bestämma vad som ska betraktas som evidens är inte enkelt och skillnader föreligger mellan discipliner och utifrån vad som är i fokus för bedömningen. Granskare skiljer sig dock inte bara åt $i$ vad de tillmäter värde och hur, utan även i sina uppfattningar om vad som är mer eller mindre svårt att bedöma (Forsberg et al., 2019).

Flera problem har uppmärksammats i samband med rekryteringar. Vid sidan av olika epistemiska och sociala bias och konservatism har framförts tillkortakommande vad gäller tillförlitlighet och effektivitet (Bornmann, 2013). I samband med detta har krav rests på formalisering, standardisering, transparens och öppenhet (Tennant \& Ross-Hellauer, 2020). Något som också öppnat för en ökad, men av flera kritiserad användning av olika kvantitativa indikatorer och mått (antal publikationer, tidskrifters 'impact factors', citeringar etc.). Ibland omtalas kollegial bedömning vid rekrytering som sekundär 'peer review' som gör bruk av resultaten från primära 'peer review' (publikationer, externfinansierade forskningsprojekt). På detta sätt integreras primära och sekundära bedömningar (Helgesson, 2016).

Granskarnas utvärderingar resulterar i dokumenterade bedömningar, så kallade sakkunnigutlåtanden, i vilka bedömningar redovisas och rättfärdigas. Det sätt på vilket olika element mobiliseras beror på typen av rekrytering, institutionella och disciplinära variationer (Levander, 2017; Levander et al., 2019). Sakkunnigutlåtandet ingår i en kedja av texter, i ett system av intertextualitet som rymmer performativa och normerande texter. Här ingår till exempel utlysningstexter, vägledningar, ansökningshandlingar med $\mathrm{CV}$, publikationer, intyg och portfolios, sakkunnigutlåtande och beslut (Chen \& Hyon, 2005). Utlătandena har både en performativ och normativ funktion. Blicken riktas omväxlande mot dåtid, samtid och framtid och följer sökandes karriärbanor mellan positioner, lärosäten och länder. Tid, rum och mobilitet är således centrala kategorier $\mathrm{i}$ de narrativ som skapas $\mathrm{i}$ de kollegiala bedömningarna (Hammarfelt et al., 2020).

Granskningar av kollegor är en delikat sak där sociala relationer måste beaktas samtidigt som möjligheten att framföra kritik värnas. Hur 
sakkunnigutlåtanden utformas och skrivs har också att göra med det maktspel som det ingår i och att det endast finns ett begränsat utrymme för att redovisa och legitimera sina förslag. Att analysera innebörden i sakkunnigutlåtanden kräver kunskap om såväl det specifika sammanhanget de är del av som de genrer och den retorik som nyttjas i rekryteringsprocesser (Paltridge, 2017; Korum, 2020). Givet sakkunnigas centrala roll vid tillsättningar aktualiseras frågan om vad som kvalificerar någon som granskare, som akademins grindvakt vid rekrytering av universitetslärare.

\section{GRINDVAKTERNA - UPPDRAG OCH KVALIFIKATIONSGRUNDER}

Den kollegiala bedömningen vilar på den grundläggande principen att kollegor (peers) utifrån en särskild expertis inom ett område bedömer andra kollegors prestation inom detta område, det vill säga en bedömning av likar. I denna praktik får vissa kollegor en särskild väktarfunktion (Merton, 1942/1973). Även om rekryteringsprocessen såsom den beskrivits ovan som helhet inrymmer en rad olika aktörer som fungerar som grindvakter på olika nivåer, är en av de mest inflytelserika aktörerna just de sakkunniga. De bevakar ingångarna till den akademiska professionen och förväntan är att de som grindvakter ska tjäna som garant för akademisk kvalitet och excellens. I förlängningen handlar det om vilken kunskap som akademin prioriterar, ger utrymme för och utvecklar och vilken kunskap som negligeras, hamnar i bakgrunden eller till och med avvecklas.

Systemet vilar på, och är beroende av aktörernas tillit till systemet. En viktig dimension här är de sakkunnigas kvalifikationer. Av hävd har sakkunniga haft samma eller högre rang än den vars prestation skall bedömas. Traditionellt sett har också sakkunniga valts med hänvisning till ämneskompetens lojaliteten har därmed riktats mot kunskapsområdet och bedömningarnas legitimitet har vunnits inom disciplinen (Askling, 2007). I takt med ökat antal anställningar och sakkunniguppdrag de senaste decennierna får sakkunniga emellertid i högre grad än tidigare i uppdrag att bedöma sökanden som inte är inom samma område som de själva. Allt oftare får granskarna bedöma sökanden vars forskningsområde överlappar, relaterar eller angränsar till sakkunnigas (Kaltenbrunner \& de Rijcke, 2019). Med inrättande av skilda excellenssystem och strävan att höja undervisningens meritvärde har gränserna för vad som kvalificerar en kollega som sakkunnig suddats ut ytterligare. I vissa fall räcker det inte längre att ha djup ämneskompetens, ämnesdidaktisk och högskolepedagogisk kompetens framhålls allt oftare som en viktig kvalifikation (Forsberg et al., 2019).

När det gäller det sätt på vilket sakkunniga erövrar erforderlig bedömarkompetens kan vissa variationer urskiljas. Till exempel är det vanligt när det gäller bedömning av vetenskaplig skicklighet att sakkunniga genom informellt och kollegialt lärande socialiserats in i bedömningspraktiken under lång tid via 
reguljär seminarieverksamhet m.m., medan sakkunniga i samband med bedömning av pedagogisk skicklighet ibland behöver genomgå formell utbildning för att komma ifråga som sakkunnig. Vem som kvalificerar sig som sakkunnig beror på vem som har auktoritet att reglera aktiviteten som granskningen äger rum i och vem som kan föreslå och slutligen välja sakkunnig. Det finns numera också ett inslag av självselektion, bland annat på grund av den stora ökningen av granskningar och meriteringsvärdet för juniora forskare. Även mindre goda villkor och tidspress har framförts som skäl till varför alltfler seniora forskare tackar nej till uppdrag (Langfeldt \& Kyvik, 2015). I sammanhanget har också framförts argument för att betrakta kollegial bedömning som en fråga om 'scholarly exchange value' där det är en akademisk plikt och skyldighet att både granska och bli granskad (Caputo, 2019).

\section{MED BLICKEN I BACKSPEGELN OCH SIKTET INSTÄLLT PÅ FRAMTIDEN}

Som framgår ovan är kollegial bedömning vid rekrytering ett $\mathrm{i}$ många avseenden komplext fenomen. Medan anställningsprocesser och dess villkor länge varit föremål för arbetslivsforskning är det främst under senare tid som rekrytering och befordran i akademin uppmärksammats (Musselin, 2010). En rad komparativa studier som initierades 1992, 2007 och 2017 har uppmärksammat formeringen av den akademiska professionen. Förändrade villkor och nya utmaningar för både akademin och professionen har noterats (Teichler \& Cummings, 2015). Professionen befinner sig dels i en kontext som utmärks av såväl stabilitet och variation som förändring och konvergens, dels i ett korstryck mellan externa krav från kunskapssamhället på samhällelig relevans och interna traditionella förväntningar på akademisk frihet.

Även om rekrytering är en vital aspekt av det som har beforskats, har inte den kollegiala granskningen varit i centrum för dessa studier. Snarare har akademikermarknaden och frågor om identitet och karriärvägarnas infrastruktur varit i fokus. Av den akademiska professionens olika roller är väktarrollen, rollen som 'peer review', alltjämt den minst undersökta. Peer review beskrivs $\mathrm{i}$ översikter som ett framväxande och fragmentariskt forskningsfält som domineras av forskare med hemvist i USA, av vissa ämnen (vetenskapssociologi, filosofi, biomedicin och scientometri), av vissa bedömningspraktiker (främst av artikelmanus och forskningsansökningar).

Medan 'peer review'-forskningen var särskilt begränsad före 1970 så har den ökat kraftigt efter 2004 och fortsätter att så göra. Bland tidiga bidrag återfinner vi klassiska vetenskapsstudier där frågor om erkännande, status och belöningssystem är föremål för analys. Hit hör också disciplinstudier och undersökningar av epistemiska kulturer och akademiska normer. Tidigt genomfördes också studier inom utvärderingsforskningen som har relevans särskilt för sättet att begreppsliggöra kollegial bedömning. Senare följs detta 
av så kallade 'evaluation and valuation studies' och undersökningar inom fälten för 'bibliometrics, infometrics och scientometrics'. Frekvent och över tid har också bedrivits makt- och mångfaldsstudier med fokus på olika former av bias sett utifrån genus, etnicitet, klass och geografisk rättvisa. Även studier av procedural och distributiv rättvisa kan räknas hit. ${ }^{2}$

Kollegial bedömning vid rekrytering är ett forskningsområde som i många delar alltjämt är underbeforskat, även om vi under det senaste decenniet har kunnat iaktta ett ökat intresse. Eftersom väktarrollen är central för den akademiska professionen är det särskilt angeläget att utveckla ett mer systematiserat och differentierat vetande om 'peer review'. Av stor betydelse är att öppna rekryterings- och bedömningsprocessens svarta låda. Kunskapen om selektion av granskare och konsekvenserna av expansionen av vem som kan kvalificera sig som 'peer' är otillräcklig. I mycket stor utsträckning saknas också analyser av texter som utbyts i processerna. Det sammanhänger delvis med att det centrala källmaterialet i rekryteringsprocesser i merparten länder inte är tillgängligt på grund av krav på konfidentialitet. Tack vare sakkunniginstitutionen, offentlighetsprincipen och krav på arkivering har vi i Sverige unika möjligheter att göra ett bidrag till det internationella forskningsfältet och utveckla kunskap om den kollegiala bedömningens svarta låda.

Behov finns också att vidga det empiriska fältet för studier och integrera studier inom samhällsvetenskaperna, humaniora, konst och pedagogiska kunskapsområdet. Komparativa studier behövs, inte bara mellan länder, utan också mellan olika typer av lärosäten, discipliner, tvärvetenskapliga kunskapsområden och mellan granskningar med skilda bedömningsfokus (vetenskaplig och/eller pedagogisk skicklighet samt administrativ och ledningskompetens).

Särskilt viktigt är att studera hur bruket av nya bedömningsredskap (metrics av skilda slag) interagerar med klassisk peer review. Viktigt är då att följa och kritiskt granska hur olika former för standardisering samspelar med eller motverkar möjligheten för granskare att bruka sitt professionella omdöme. Av avgörande betydelse är också hur balansen dem emellan på kort och lång sikt påverkar akademin och dess bidrag till det omgivande samhället. Sammanfattningsvis har vi framför oss komplexa, mångfacetterade, intressanta och utmanande forskningsuppgifter som kräver flerfaldiga metodologiska ansatser.

\section{NOTER}

${ }^{1}$ Denna text har sin grund i presentationen Kollegial bedömning vid rekrytering och befordran vid SWERA:s årliga konferens den 7-8 oktober 2020. Texten utgör därmed noteringar och några mer utvecklade resonemang kring ett för den akademiska 
professionen och för forskning om högre utbildning centralt objekt. Se också Forsberg et al. (u.u.).

${ }^{2}$ För översikter av peer review-forskningen se t.ex. Batagelj et al. (2017), Grimaldo et al. (2018) och Sabaj Meruane et al. (2016).

\section{REFERENSER}

Askling, Berit (2007). Om sakkunskap och expertis i nationella utvärderingar och kvalitetsbedömningar. Göteborgs universitet.

Batagelj, Vladimir, Ferligoj, Anuška, \& Squazzoni, Flaminio (2017). The emergence of a field: a network analysis of research on peer review. Scientometrics, 113:503-532. DOI 10.1007/s11192-017-2522-8

Becher, Tony (1989). Academic Tribes and Territories: Intellectual Inquiry and the Cultures of Disciplines. Milton Keynes: SRHE/OUP.

Bornmann, Lutz (2013). Evaluations by peer review in science. Springer Science Reviews, 1(1-4). DOI 10. 1007/s40362-012-0002-3.

Bourdieu, Pierre (1996). Homo academicus. Polity.

Caputo, Richard K. (2019). Peer Review: A Vital Gatekeeping Function and Obligation of Professional Scholarly Practice. Families in Society: The Journal of Contemporary Social Services, 100(1), 6-16. DOI: $10.1177 / 104438941880815$

Chen, Rong, \& Hyon, Sunny (2005). Faculty evlauation as a genre system: negotiating intertextuality and interpersonality. Journal of Applied Linguistics, 2.2, 153-184. DOI: 10.1558/japl.2005.2.2.153

Clark, Burton R. (1989). The Academic Life: Small Worlds, Different Worlds. Educational Researcher, 18(5), 4-8.

Cole, Jonathan R., \& Cole Stephen (1973). Social Stratification in Science. University of Chicago Press.

Czizar, Alex (2016). Troubled from the start. Nature, 532, 306-308.

Forsberg, Eva, Levander, Sara, \& Elmgren, Maja (u.u.). Peer review in academic promotion of excellent teachers. I Eva Forsberg, Lars Geschwind, Sara Levander, \& Wieland Wermke (red.), Peer Review in an Era of Evaluation. Understanding of the practice of Gatekeeping in Academia. Palgrave MacMillan. 
Forsberg, Eva, Geschwind, Lars, Levander, Sara, \& Wermke, Wieland (u.u.). Peer Review in an Era of Evaluation. . Understanding of the practice of Gatekeeping in Academia. Palgrave MacMillan.

Grimaldo, Francisco, Marušić, Ana, \& Squazzoni, Flaminio (2018). Fragments of peer review: A quantitative analysis of the literature (19692015). PLoS ONE, 13(2): e0193148. DOI: https://doi.org/10.1371/journal. pone.0193148

Hammarfelt, Björn, \& Rushforth, Alexander D. (2017). Indicators as judgment devices: An empirical study of citizen bibliometrics in research evaluation. Research Evaluation, 26(3), 169-180. https://doi.org/10.1093/reseval/rvx018

Hammarfelt, Björn, Rushforth, Alexander D., \& de Rijcke, Sarah (2020). Temporality in Academic Evaluation: 'Trajectoral Thinking' in the Assessment of Biomedical Researchers. Valuation Studies, 7(1): 33-63.

Helgesson Claes-Fredrik (2016). Folded Valuations? V aluation Studies, 4(2), 93-102.

Kaltenbrunner, Wolfgang, \& de Rijcke, Sarah (2019). Filling in the gaps: The interpretation of curricula vitae in peer review. Social Studies of Science, 49(6), 863-883. doi:10.1177/0306312719864164

Korom, Philipp (2020). The Talented Writer Robert K. Merton as a Powerful Gate-Opener: An Analysis of 1,460 Recommendation Letters. Zeitschrift für Soziologie, 49(4), 249-264. doi.org/10.1515/zfsoz-2020-0022

Lamont, Michèle (2009). How professors think. Inside the curious world of academic judgment. Harvard University Press.

Langfeldt, Liv, \& Kyvik, Svein (2011). Researchers as Evaluators: Tasks, Tensions and Politics. Higher Education, 62(2), 199-212.

Langfeldt, Liv, \& Kyvik, Svein (2015). Intrinsic tensions and future challenges of peer review. RJ Yearbook 2015/2016.

Langfeldt, Liv, Nedeva, Maria, Sörlin, Sverker \& Thomas Duncan A. (2020). Co-existing notions of research quality: A framework to study contextspecific understandings of good research. Minerva, 58, 115-137. doi: 10.1007/s11024-019-09385-2.

Levander, Sara (2017). Den pedagogiska skickligheten och akademins väktare: Kollegial bedömning vid rekrytering av universitetslärare. [Doktorsavhandling]. Uppsala universitet.

Levander, Sara, Forsberg, Eva, \& Elmgren, Maja (2019). The meaningmaking of educational proficiency in academic hiring: a bland spot in the 
black box. Teaching in Higher Education, 25(5), 541-559.

doi.org/10.1080/13562517.2019.157660.

Merton Robert K. (1942/1973). A note on science and democracy. Journal of Legal and Political Sociology 1942;1, 115-126.

Merton, Robert K. (1968). The Matthew Effect in Science. Science 159(3810): 56-63.

Musselin, Christine (2010): The Market for Academics. Routledge.

Oancea, Alis (2019). Research governance and the future(s) of research assessment. Palgrave communications, 5, 27, 1-12. doi.org/10.1057/s41599018-0213-6.

Paltridge, Brian (2017). The Discourse of Peer Review. Reviewing Submission to Academic Journals. The MacMillan Publishers Ltd.

Sabaj Meruane, Omar, González Vergara, Carlos, \& Pina-Stranger, Álvaro (2016). What We Still Don't Know About Peer Review. Joumal of Scholarly Publishing, 47(2), 180-212. doi:10.3138/jsp.47.2.180

Scriven, Michael (2003). Evaluation theory and metatheory. I T. Kellaghan, D.L. Stufflebeam, \& L.A. Wingate, (red.), International Handbook of Educational Evaluation (s. 15-30). Kluwer Academic Publishers.

Teichler, Ulrich, \& Cummings, William K. Eds (2015). Forming, Recruiting and Managing the Academic Profession. Springer.

Teichler, Ulrich, \& Höhle, Ester A. (red.) (2013). The work situation of the academic profession: Findings of a survey in twelve European countries. Springer.

Tennant, Jonathan P., \& Ross-Hellauer, Tony (2020). The limitations to our understanding of peer review. Research Integrity and Peer Review, 5, 6, 1-14 https://doi.org/10.1186/s41073-020-00092-1

Whitley, Richard (2011). Changing Governance and Authority Relationships in the Public Sciences. Minerva, 49(4): 359-385.

Ziman, John (1968). Public Knowledge: An Essay Concerning the Social Dimension of Science. Cambridge University Press. 